\title{
Efecto del método de extracción de antocianinas de la flor de Jamaica (Hibiscus sabdariffa) en la eficiencia de celdas solares sensibilizadas
}

\author{
*Sangoluisa Mirian', Santacruz Cristian², Salvador Marcelo ${ }^{1}$
}

'Escuela Politécnica Nacional, Facultad de Ingeniería Química, Quito, Ecuador

${ }^{2}$ Escuela Politécnica Nacional, Facultad de Ciencias, Quito, Ecuador

*Autor Principal/Corresponding Author, e-mail: mirian.sangoluisa@epn.edu.ec

\section{Effect of extraction method of anthocyanins from the hibiscus flower (Hibiscus sabdariffa) on the efficiency of dye-sensitized solar cells}

\begin{abstract}
Resumen
Los pigmentos naturales podrían ser una opción viable como materiales fotosensibles en celdas solares electroquímicas. El presente trabajo evalúa el efecto del método de extracción y purificación de los pigmentos de la flor de Jamaica (Hibiscus sabdariffa) en la eficiencia energética de celdas solares electroquímicas. Para este fin, los pigmentos fueron extraídos con metanol acidificado utilizando tres diferentes ácidos: ácido clorhídrico, ácido cítrico y ácido trifluoroacético. La evaluación del contenido de antocianinas totales reveló que el ácido clorhídrico es el solvente más eficiente en el proceso de extracción. Mediante técnicas de cromatografía se identificaron dos antocianinas en los extractos de la flor de Jamaica, cianidina 3-sambubiósido y delfinidina 3-sambubiósido. La evaluación de la eficiencia de conversión energética de celdas solares sensibilizadas con estos pigmentos reveló que la extracción con ácido clorhídrico produce celdas con mayor eficiencia. Mediante un proceso de purificación con hexano se determinó que los residuos no polares existentes en los extractos no influyen en el desempeño de la celda; sin embargo, residuos del solvente aparentemente sí la afectan. Finalmente se determinó que las celdas solares no tienen gran estabilidad en el tiempo, teniendo una tendencia creciente en las primeras 72 horas y un posterior decrecimiento.
\end{abstract}

Editado por /

Edited by:

Diego F. Cisneros Heredia

Recibido /

Received:

2017-05-03

Aceptado /

Accepted:

2019-03-12

Publicado en línea Published online: 2019-04-18
Palabras clave: Flor de Jamaica, pigmento, antocianina, sensibilizador, DSSC, eficiencia energética

\section{Abstract}

Natural dyes could be an option as sensitizers in electrochemical solar cells. Herein, the effect of the extraction and purification methods of dyes of the hibiscus flower on the energy conversion efficiency of dye-sensitized solar cells (DSSC) has been evaluated. The pigments were extracted with methanol acidified with hydrochloric acid, citric acid or trifluoroacetic acid. The total anthocyanin content was evaluated, 
and it was found hydrochloric acid produces the best extraction efficiency. The two possible anthocyanin's found by chromatography were cyanidin 3-sambubioside and delphinidin 3-sambubioside. Both dyes were used as photosensitizers in DSSC and their energy conversion efficiencies were evaluated. The DSSC that use dyes extracted using hydrochloric acid has the highest efficiency. It was found that the non-polar residues do not affect the performance of the DSSC by removing them with hexane. The stability of the solar cells with time was determined by measuring the energy efficiencies for 30 days; observing an increasing trend in the first 72 hours, and then a decreasing trend.

Keywords: Hibiscus sabdariffa, pigment, anthocyanin, sensitizer, DSSC, energy efficient

\section{INTRODUCCIÓN}

Las celdas solares sensibilizadas con colorantes (Dye Sensitized Solar Cells o DSSC) son dispositivos utilizados para la conversión de luz solar en electricidad, los cuales se basan en la fotosensibilización de semiconductores de óxido mesoporoso [1]. Las DSSC fueron desarrolladas por Michael Grätzel y Brian O'Regan en 1991, introduciendo este nuevo concepto innovador y de bajo costo [2]. Grätzel y O'Regan basaron las DSSC en un semiconductor de $\mathrm{TiO}_{2}$ nanoparticulado en fase anatasa sensibilizado con un tinte de rutenio y utilizaron como electrolito un par redox $1 / /^{3-\text { or }}$ obteniendo una eficiencia de $7,12 \%$ a una intensidad de $750 \mathrm{~W} / \mathrm{m}^{2}$ [3].

La estructura básica de una DSSC involucra a un electrodo, un electrolito y un contraelectrodo. El electrodo es un sustrato transparente conductor, impregnado con una película semiconductora fotosensible que absorbe la luz solar, genera carga eléctrica y la transporta. El semiconductor más utilizado para transportar la carga eléctrica es el dióxido de titanio nanoparticulado $\left(\mathrm{TiO}_{2}\right)$, debido a sus propiedades de estabilidad y resistencia a la corrosión y descomposición en presencia de reacciones foto-electroquímicas. $\mathrm{EITiO}_{2}$ no es capaz de absorber la luz visible, por lo que se foto-sensibiliza recubriéndolo con una película de moléculas absorbentes en el rango visible o infrarrojo [4]. El electrolito es un compuesto generalmente líquido que se encarga de reducir el colorante oxidado debido a la absorción de la luz solar y emisión de carga eléctrica [5]. El electrolito más utilizado en las DSSC es una solución de yoduro (I-/I3-), que presenta una absorción de luz relativamente baja; sin embargo, tiende a perder los iones triyoduro (I3-), lo cual provoca la disminución de la eficiencia de la celda a largo plazo [6]. El contra-electrodo consta de un sustrato transparente conductor recubierto de un catalizador, usualmente platino, que ayuda en la reducción del I3- producido en la oxidación del electrolito [2].

En la Fig. 1 se muestra el principio de operación de una DSSC. La conversión energética se da cuando un pigmento "anclado" al semiconductor absorbe la luz solar y se excita inyectando un electrón a la banda de conducción del $\mathrm{TiO}_{2^{\prime}}$ oxidando al pigmento [7]. El pigmento oxidado regresa a su estado basal reduciéndose en el electrolito, el que a su vez es regenerado en el contraelectrodo, completando así el circuito mediante la migración de electrones a través de la carga externa [8]. 
Figura 1. Representación esquemática del funcionamiento de una DSSC. El ciclo de transformación directa de luz en electricidad comienza con la fotoexcitación del pigmento que pasa del estado basal $S$ al estado de excitación $\mathrm{S}^{*}$, entonces un electrón es inyectado en la banda de conducción del semiconductor $\left(\mathrm{TiO}_{2}\right)$. El pigmento oxidado $\mathrm{S}^{+}$se reduce en el yoduro (I-) del electrolito líquido generando triyoduro (I3-) que se reduce en el catalizador de platino del contraelectrodo [8].

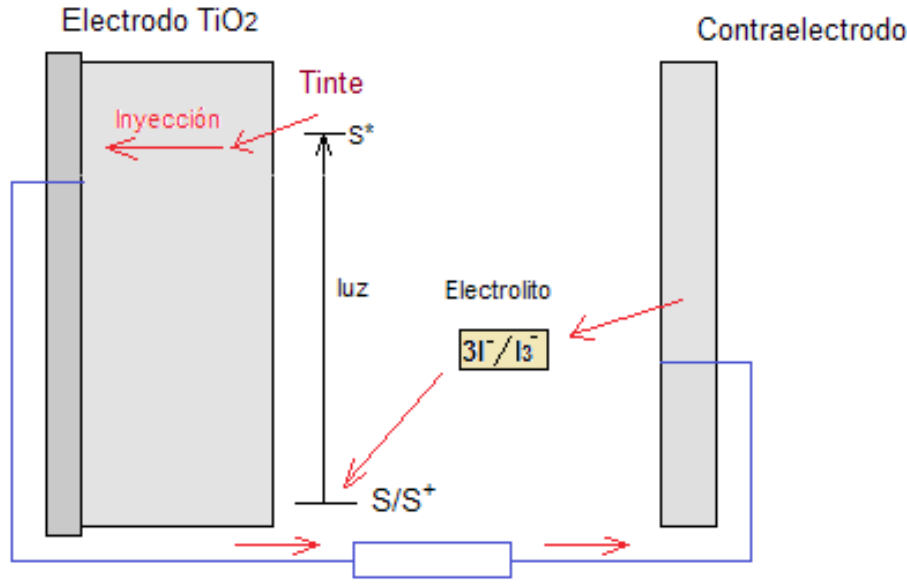

Los pigmentos, sintéticos o naturales, cumplen un papel importante en el rendimiento de las DSSC, para captar los fotones de la luz solar, deben poseer las siguientes características especiales: absorber en un amplio espectro de luz visible, tener un potencial de energía de excitación similar al de la banda de conducción del semiconductor, presentar en su estructura grupos funcionales para anclarse al dióxido de titanio $(-\mathrm{COOH}$ o $-\mathrm{OH})$ y tener buena estabilidad química y térmica [9]. Entre los pigmentos sintéticos se encuentran complejos metálicos de rutenio (Ru) y zirconio (Zr), no obstante, su costo de síntesis es muy alto. Por esta razón, se los ha sustituido como sensibilizadores en DSSC con pigmentos naturales ya que son fáciles de obtener, no son tóxicos y son biodegradables [10].

Las antocianinas son las estructuras responsables del color de los pigmentos naturales. Su estructura presenta grupos hidroxilo $(-\mathrm{OH})$ que pueden servir de anclaje con las partículas de $\mathrm{TiO}_{2}$ de las DSSC [12]. Actualmente se conocen aproximadamente 20 diferentes antocianinas, entre las cuáles las más importantes son la pelargonidina, delfinidina, cianidina, petunidina, peoidina y malvidina; éstas pueden combinarse con diferentes azúcares y formar alrededor de 150 tipos de antocianinas. Los monosacáridos más comunes presentes en las antocianinas son la arabinosa, xilosa y glucosa; mientras que los disacáridos más comunes son la sambubiosa y rutinosa [11]. La estabilidad de las antocianinas depende de diferentes factores como su estructura, el pH, temperatura, longitud de onda y oxígeno.

El pigmento de la flor de Jamaica (Hibiscus sabdariffa) ha sido utilizado como sensibilizador en DSSC y se han reportado eficiencias de alrededor de 0,107\% [13]. El pigmento es extraído de las flores de Jamaica, donde se encuentran la mayor cantidad de antocianinas presentes en esta planta que le dan su característico color rojo intenso. Las antocianinas que han sido identificadas son la cianidina 3-sambubiósido (hibiscin) 
y delfinidina 3-sambubiósido, cuyas estructuras se presentan en la Fig. 2 y que han de anclarse con el semiconductor de las DSSC mediante sus enlaces -OH [14]. El presente artículo cuantifica la eficiencia de extracción de las antocianinas de la flor de Jamaica con el tipo de ácido utilizado en su aislamiento, su caracterización mediante técnicas cromatográficas y su evaluación como sensibilizadores en celdas solares.

Figura 2. Representación esquemática de la estructura de las antocianinas presentes en el pigmento de flor de Jamaica (Hibiscus Sabdariffa): A) Cianidina 3-sambubiósido y B) Delfinidina 3-sambubiósido. En estas estructuras se observa el anillo ubicado en la parte superior derecha de cada imagen correspondiente al grupo funcional de anclaje (-OH) con el óxido semiconductor en un DSSC.

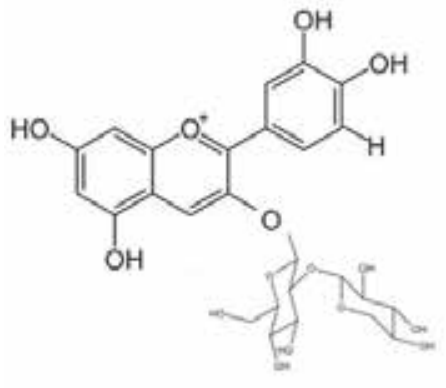

Cisnidina 3-sambebibsido<smiles>C=CCN(CCCC)Oc1cc2c(O)cc(O)cc2[o+]c1-c1cc(O)c(O)c(O)c1</smiles>

Delfinidina 3-sambubiósido

A) B)

\section{MATERIALES Y MÉTODOS}

La flor de Jamaica (Hibiscus sabdariffa) fue adquirida en la provincia de Morona Santiago en el Ecuador. Los reactivos utilizados para la extracción, caracterización e identificación en capa fina de los pigmentos (metanol, ácido clorhídrico, ácido cítrico, ácido trifluoroacético, ácido fórmico y n-butanol) fueron de grado analítico (SIGMA-ALDRICH). El estándar cianidin-3-glucosid chlorid $97 \%\left(\mathrm{C}_{21} \mathrm{H}_{21} \mathrm{ClO}_{11}\right)$ para capa fina fue proveído por PHYTOPLAN. Los eluyentes para HPLC (acetonitrilo, agua y ácido fosfórico) fueron de grado HPLC. Los materiales utilizados en la construcción de celdas solares (vidrio FTO, resina selladora, solución de electrolito, solución de platino, entre otros) fueron adquiridos en Solaronix.

\section{Preparación y caracterización de la muestra}

La flor de Jamaica deshidratada fue molida hasta obtener un polvo fino. La muestra, fue caracterizada determinando el $\mathrm{pH}$, acidez titulable y sólidos solubles totales. El pH se midió aplicando el método AOAC 10.035: se pesaron $5 \mathrm{~g}$ de la muestra y se disolvieron en $25 \mathrm{~mL}$ de agua destilada, y se midió directamente con un potenciómetro (Inolab WTW) [15]. La acidez titulable se determinó mediante el método AOAC 22.061: se pesó $1 \mathrm{~g}$ de muestra y se diluyó en $40 \mathrm{~mL}$ de agua destilada; se tituló una alícuota de $25 \mathrm{~mL}$ con $\mathrm{NaOH} 0,1 \mathrm{~N}$ [16]. La cantidad de sólidos solubles totales se determinó aplicando la norma ISO 2173:2003: se pesó $1 \mathrm{~g}$ de muestra y se diluyó en $10 \mathrm{~mL}$ de agua destilada; se utilizó un refractómetro BOECO (0-40Brix) [17]. 


\section{Extracción de pigmentos}

El solvente empleado en la extracción fue metanol acidificado. Los ácidos utilizados fueron: ácido clorhídrico $(\mathrm{HCl})$, ácido cítrico y ácido trifluoroacético (TFA). Se prepararon las siguientes soluciones: metanol- $\mathrm{HCl}$ 0,01\% v/v, metanol-ácido cítrico 1,05\% w/v y metanol-TFA 0,5\% v/v. La cantidad de ácido fue añadida con el fin de que el metanol alcance un pH ácido, llegando a valores menores a 4 [18-19]. Se pesaron $20 \mathrm{~g}$ de flor de Jamaica pulverizada y se añadieron $100 \mathrm{~mL}$ de metanol acidificado, se mantuvo en agitación constante por una hora y se filtró en un embudo Buchner al vacío. Se realizaron 5 extracciones consecutivas, añadiendo $100 \mathrm{~mL}$ de metanol en cada extracción y se concentró el pigmento a $100 \mathrm{~mL}$ en un rotavapor IKA RV 10 a $150 \mathrm{mbar}$ y $40^{\circ} \mathrm{C}$ [20-21].

\section{Cuantificación de los pigmentos de la flor de Jamaica}

Los espectros de absorción fueron obtenidos colocando el pigmento en cubetas de cuarzo de $10 \mathrm{~mm}$ de longitud con un barrido espectral entre 350 y $700 \mathrm{~nm}$ (VARIAN 50 Bio). Se cuantificó el contenido total de antocianinas mediante el método de pH diferencial utilizando las ecuaciones (1) y (2). Se prepararon dos soluciones buffer: una de $\mathrm{KCl} 0,025 \mathrm{M}$ ajustando el $\mathrm{pH}$ a $1 \mathrm{con} \mathrm{HCl}$ y otra de acetato de sodio 0,5 $\mathrm{M}$ ajustando el pH a 4,5 con ácido acético.

$$
A=\left(A_{\lambda M a \dot{x}}-A_{700}\right)_{p H 1}-\left(A_{\lambda M a ́ x}-A_{700}\right)_{p H 4,5}
$$

Donde $A$ es el espectro de absorción del pigmento, $A_{\text {גmáx }}$ es la absorbancia a la longitud de onda máxima y $A_{700}$ es la absorbancia a la longitud de onda de $700 \mathrm{~nm}$ [18].

$$
\text { Contenido de antocianinas }(w / w)=\frac{A \times P M \times F D \times 100}{\varepsilon \times 1}
$$

Donde $P M$ es el peso molecular cianidina $(449,2 \mathrm{~g} / \mathrm{mol}) ; \varepsilon$ es el coeficiente de absortividad (26 $\left.900 \mathrm{~L} / \mathrm{cm}^{*} \mathrm{~mol}\right) ;$ FD es el factor de dilución.

\section{Cromatografía de capa fina (TLC)}

Se utilizaron placas de sílica gel 60F de $10 \times 10 \mathrm{~cm}$, se sembró la muestra (pigmento de flor de Jamaica extraído con metanol-HCl) y el estándar de cinianidin-3-glucosid chlorid con un inyector automático (CAMAG Linomat 5). La fase móvil fue una solución de ácido fórmico, agua y n-butanol (10:15:40); una vez terminada la separación se marcaron las bandas separadas y se midieron las distancias recorridas de las bandas y del solvente, para el posterior cálculo de las relaciones de frentes o Rf [22]. La identificación de las antocianinas separadas se realizó mediante la técnica de Woodward-Fieser, que estima el tipo de antocianina midiendo la longitud de onda y absorbancia máxima. Para lo cual, se recolectaron las bandas separadas en frascos ámbar, se eluyó con metanol y se filtró. Se realizó un barrido espectral y se determinó la longitud de onda máxima [23].

\section{Cromatografía líquida de alta eficiencia (HPLC)}

Se utilizó un equipo DIONEX Ultimate 3000 con detector UV-VIS, una columna C-18 de polisiloxano de $3 \mu \mathrm{m}, 300 \AA$ y 4,6x150 mm. Las fases móviles utilizadas fueron acetonitrilo 
(Fase A) y una solución de ácido fosfórico al 4\% (Fase B). Se utilizó un flujo de $1 \mathrm{~mL} / \mathrm{min}$ y el siguiente gradiente: $0-10$ minutos $4 \%$ de $A$ y $96 \%$ de $B$; $10-55$ minutos $4 \%$ de $A$ y $96 \%$ de $B ; 55-65$ minutos $25 \%$ de $A$ y $75 \%$ de B y $65-70$ minutos 4 de $\%$ A y $96 \%$ de B. La muestra se preparó diluyendo el pigmento de flor de Jamaica con agua tipo I y se filtró en discos Whatman de 0,2 $\mu \mathrm{m}$. Se inyectaron $50 \mu \mathrm{L}$ de la muestra y se detectaron las antocianinas en $514 \mathrm{~nm}[21]$.

\section{Purificación de pigmentos}

Los pigmentos de flor de Jamaica acidificados con $\mathrm{HCl}$, ácido cítrico y TFA fueron lavados tres veces con hexano con el fin de remover compuestos orgánicos como lípidos, carotenoides y clorofilas. Se utilizó una relación en volumen 1:1 entre la muestra y hexano, se colocó en un embudo de separación $10 \mathrm{~mL}$ de la muestra y $10 \mathrm{~mL}$ de hexano, se agitó destapando el embudo para eliminar vapores y se dejó reposar el embudo para separar y eliminar la fase orgánica. Se concentró el pigmento en un rotavapor para eliminar los restos de hexano [24].

\section{Depósito y caracterización de películas de dióxido de titanio nanoparticulado ( TiO $_{2}$ )}

Se utilizaron placas de vidrios de óxido de estaño dopado con flúor (FTO, por sus siglas en inglés) de $15 \Omega / \mathrm{Sq}$. (TCO22-15, Solaronix) de $2 \times 1 \mathrm{~cm}$. Se impregnaron 3 capas de dióxido de titanio nanoparticulado difuso $\left(\mathrm{TiO}_{2}\right.$ Difuse, Solaronix) de 5,5×5,5 mm en el lado conductor del vidrio FTO mediante la técnica de serigrafía utilizando una malla SEFAR PET 1500, N 77/195-55 PW. Cada capa se sometió a un proceso de secado a $120^{\circ} \mathrm{C}$ por 7 minutos. Luego de la última capa de $\mathrm{TiO}_{2}$ depositada se sinterizó a $450^{\circ} \mathrm{C}$ por 30 minutos subiendo la temperatura en $50^{\circ} \mathrm{C}$ por minuto. La caracterización de las películas se realizó en un microscopio de fuerza atómica (AFM, Nanosurf Naio), el cual generó una imagen topográfica de la superficie y el tamaño de las nanopartículas de $\mathrm{TiO}_{2}$ [13].

\section{Pigmentación de películas y sellado de la celda DSSC}

Las películas de $\mathrm{TiO}_{2}$ fueron sumergidas en el pigmento acidificado de flor de Jamaica por 21 horas. Se pigmentaron otros sustratos con rutenio (Ruthenizer 535-bis TBA, Solaronix) como pigmento de referencia. Se preparó el contraelectrodo con otro vidrio FTO impregnado con una solución de platino (Platisol, Solaronix) que se activó a $450{ }^{\circ} \mathrm{C}$ por 10 minutos subiendo $50^{\circ} \mathrm{C}$ cada minuto. Para sellar la celda, se utilizó una resina selladora (Meltonix 60F, Solaronix) entre el electrodo y el contraelectrodo fundiéndola a $130^{\circ} \mathrm{C}$. Seguido, se inyectó el electrolito $\left(1 / /^{3-}, \mathrm{R}-150\right.$, Solaronix $)$ a través de un orificio de $2 \mathrm{~mm}$ de diámetro. Finalmente, se selló el orificio del contraelectrodo con un pequeño pedazo de cubre-objeto y resina selladora para evitar la fuga del electrolito [13].

\section{Caracterización de DSSC}

Se utilizó un simulador solar AM 1,5 G que ilumina un área de $1 \mathrm{~cm}^{2}$ [25]. La medición de las curvas de corriente - voltaje se la realizó con una fuente de voltaje variable (Keithley Modelo 2400). Los datos fueron analizados por un programa que reporta la curva característica (Intensidad vs Voltaje) y parámetros como: corriente de corto circuito 
(Isc), voltaje de circuito abierto (Voc), factor de llenado (FF) y porcentaje de eficiencia energética ( $\eta$. Además, se determinó la estabilidad de las celdas DSSC con el tiempo, midiendo la eficiencia energética por 30 días [13].

\section{RESULTADOS}

\section{Caracterización de la flor de Jamaica}

En la Tabla 1 se presentan los resultados obtenidos de la caracterización de la muestra de flor de Jamaica pulverizada. Dicha muestra presentó un pH de 2,54; acidez titulable de $28,4 \mathrm{~g}$ de ácido málico/100g de muestra seca y un total de sólidos de 5,8 • Brix.

Tabla 1. Resultado de los valores obtenidos para el pH, acidez titulable y sólidos totales de la caracterización de la muestra de flor de Jamaica pulverizada. Se presentan los valores de las 3 repeticiones realizadas.

\begin{tabular}{|c|c|c|c|}
\hline Muestra & pH & $\begin{array}{c}\text { Acidez titulable } \\
\text { (g acido málico/100g } \\
\text { muestra seca) }\end{array}$ & $\begin{array}{c}\text { Sólidos } \\
\text { totales ( }{ }^{\circ} \text { Brix) }\end{array}$ \\
\hline 1 & 2,544 & 23,8 & 5,8 \\
\hline 2 & 2,535 & 30,0 & 5,6 \\
\hline 3 & 2,541 & 31,3 & 6,0 \\
\hline Promedio* & $2,540 \pm 0,005$ & $28,4 \pm 4,0$ & $5,8 \pm 0,2$ \\
\hline
\end{tabular}

*Valor promedio de cada propiedad de caracterización con la desviación estándar con el 95\% de confianza.

\section{Cuantificación de los pigmentos de la flor de Jamaica}

Figura 3. Espectros de absorción de los pigmentos de la flor de Jamaica extraídos con tres ácidos diferentes: $\mathrm{HCl}$, ácido cítrico y TFA. Se evidencia bandas máximas características de las antocianinas tanto en la región UV como en la región visible. Las bandas características de la región visible $(540 \mathrm{~nm})$ presentaron absorbancias de 0,$23 ; 0,41$ y 0,57 para $\mathrm{HCl}$, ácido cítrico y TFA respectivamente que se relacionan inversamente con los valores de $\mathrm{pH}$ de los pigmentos que fueron 3,$6 ; 3,0$ y 2,3 para cada ácido mencionado.

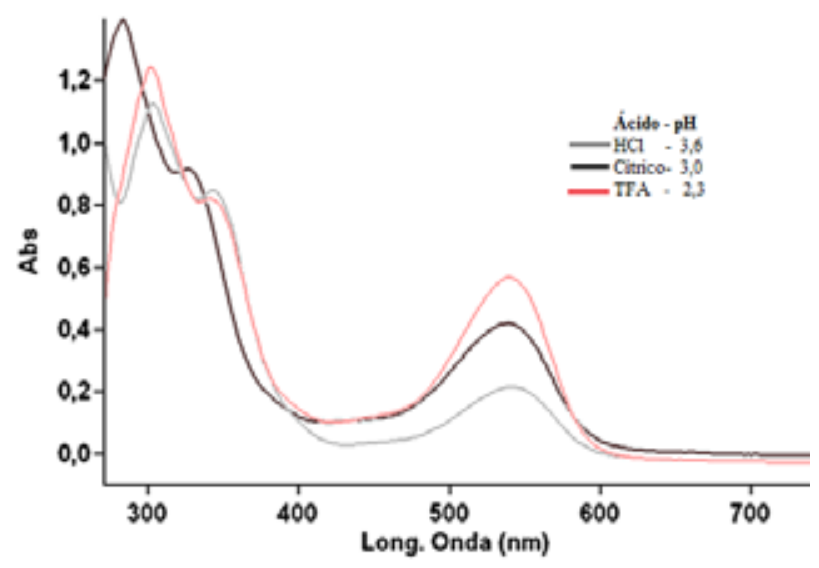


En la Fig. 3 se presentan los espectros de absorción de los pigmentos de la flor de Jamaica en metanol con los tres ácidos de extracción: $\mathrm{HCl}$, ácido cítrico y TFA. En los tres casos se observaron dos bandas características de las antocianinas: una en la región UV y una en la región visible [26]. En la región UV la banda para los ácidos HCl y TFA se encuentra a los $315 \mathrm{~nm}$; mientras que para el ácido cítrico la banda pronunciada se presentó a los $280 \mathrm{~nm}$. En la región visible la banda característica fue a los $540 \mathrm{~nm}$ para los tres ácidos utilizados. Sin embargo, en esta longitud de onda la absorbancia es diferente para cada ácido; siendo 0,23; 0,41 y 0,57 para $\mathrm{HCl}$, ácido cítrico y TFA, respectivamente.

Los resultados obtenidos de la cuantificación total de antocianinas de los pigmentos de flor de Jamaica se presentan en la Tabla 2. La extracción con HCl obtuvo la mayor cantidad de antocianinas totales, seguido de la extracción con ácido cítrico, y finalmente con TFA.

Tabla 2. Comparación del contenido total de antocianinas monoméricas en base seca de los pigmentos extraídos de la flor de Jamaica con tres diferentes ácidos: HCl. ácido cítrico y TFA.

\begin{tabular}{|c|c|}
$\begin{array}{c}\text { Ácido utilizado en la } \\
\text { extracción }\end{array}$ & $\begin{array}{c}\text { mg de antocianinas/100 g de } \\
\text { muestra seca } \\
\text { (Valor promedio*) }\end{array}$ \\
\hline Ácido clorhídrico (HCl) & $1076,4 \pm 6,7$ \\
\hline Ácido cítrico & $997,4 \pm 1,9$ \\
Ácido trifluoroacético (TFA) & $895,1 \pm 10,8$ \\
\hline *alor promedio de cada propiedad de caracterización con la desviación estándar con el 95\% de confianza.
\end{tabular}

\section{Identificación de antocianinas mediante TLC}

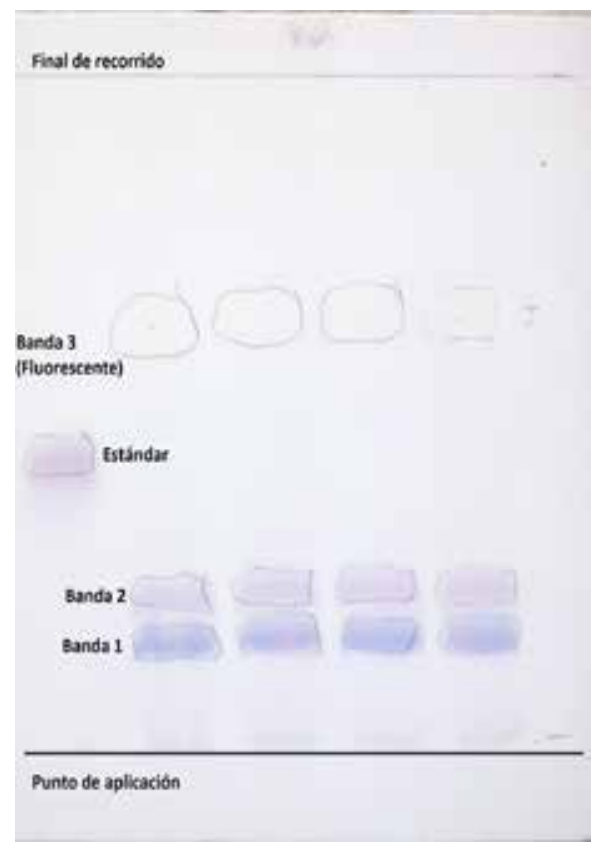

Figura 4. Fotografía de la separación de antocianinas del pigmento de flor de Jamaica en una placa de sílica gel. Fase móvil: de n-butanol, ácido fórmico y agua (10:15:40). La banda 1 corresponde a la delfinidina 3-sambubiósido, la banda 2 a la cianidina 3-sambubiósido. 
La cromatografía en capa fina del pigmento de flor de Jamaica dio como resultado la separación de tres bandas que se presentan en la fotografía de la Fig. 4, donde se observa la separación de dos bandas coloreadas que corresponderían a las dos antocianinas características de la flor de Jamaica. Sin embargo, dichas bandas no coinciden con el estándar utilizado en esta investigación debido a que éste contiene un átomo de cloro en su estructura.

Figura 5. Espectros de absorción de las dos antocianinas del pigmento de la flor de Jamaica separadas mediante TLC: A) delfinidina 3-sambubiósido, se observa la longitud de onda de la banda máxima de la región UV en 277nm y B) cianidina 3-sambubiósido, la longitud de onda de la banda máxima de la región UV en 272 $\mathrm{nm}$. Estas antocianinas servirán para corroborar el tipo de antocianina presente en la flor de Jamaica mediante la técnica de Woodward Fieser.

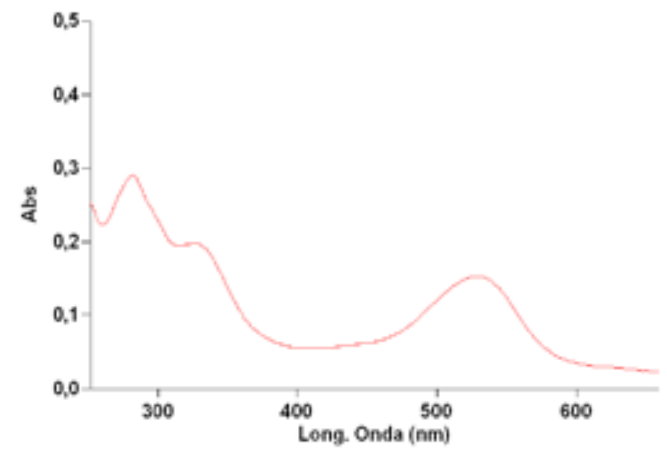

A)

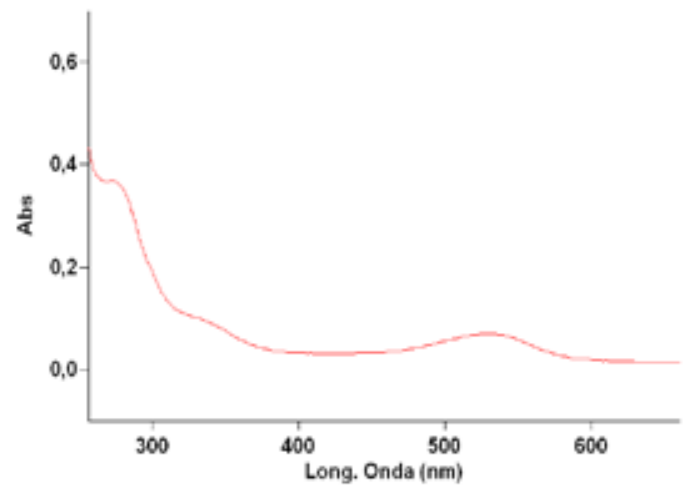

B)

Los espectros de las dos antocianinas separadas se presentan en la Fig. 5 permitieron identificar el tipo de disacárido que presenta el pigmento. Además, ayudaron en la aplicación de la regla de Woodward-Fieser al proporcionar el valor de las longitudes de onda de las bandas de absorción máxima de la región UV que fueron de 277 nm y 272 $\mathrm{nm}$ para las bandas 1 y 2 , respectivamente, y que se presentan en la Tabla 3. Además, en esta misma tabla se registraron los valores de Rf de las antocianinas separadas, utilizando como fase móvil ácido fórmico:agua:n-butanol (10:15:40). 
Tabla 3. Valores de Rf, absorbancia y longitud de onda máxima obtenidos para cada banda separada en TLC; $y$ resultados de la aplicación del método de Woodward Fieser para la identificación de las antocianinas presentes en la flor de Jamaica.

\begin{tabular}{c|c|c|c|c|c|} 
Banda & \multicolumn{1}{c}{ Rf } & Absorbancia & $\begin{array}{c}\lambda \\
(\mathbf{n m})\end{array}$ & $\begin{array}{c}\text { Woodward- } \\
\text { Fieser } \\
( \pm 5 \mathrm{~nm})\end{array}$ & $\begin{array}{c}\text { Posible } \\
\text { antocianina }\end{array}$ \\
\hline 1 & 0,14 & 0,291 & 277 & 275 & $\begin{array}{c}\text { Delfinidina } \\
\text { 3-sambubiósido }\end{array}$ \\
\hline 2 & 0,20 & 0,373 & 272 & 268 & $\begin{array}{c}\text { Cianidina 3 } \\
\text { sambubiósido }\end{array}$ \\
\hline
\end{tabular}

\section{Identificación de antocianinas mediante HPLC}

La identificación por HPLC del pigmento de la flor de Jamaica se realizó siguiendo el protocolo descrito por Laboratorios Camag [22], obteniendo el cromatograma presentando en la Fig. 6, donde se identificaron dos bandas predominantes, uno al minuto 23,220 y otro al minuto 26,804 .

Figura 6. Espectro HPLC de pigmento de la flor de Jamaica extraído con metanol-HCl diluida con un $\mathrm{FD}=10$; usando como fase móvil acetonitrilo (Fase A) y ácido fosfórico al 4\% (Fase B) por 70 minutos. Bandas 1 y 2 correspondientes a antocianinas al minuto 23,220 y 26,804 respectivamente.

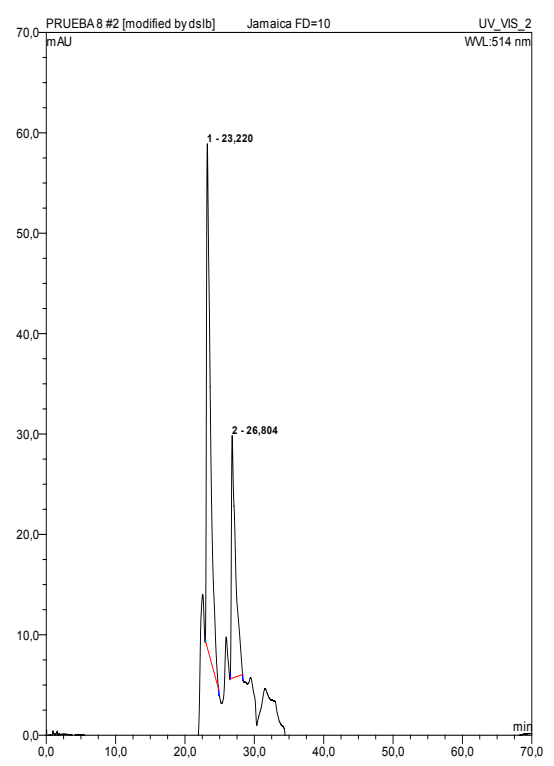

\section{Caracterización de las DDSC}

En la Tabla 3 se presentan los valores promedio de los parámetros de caracterización de celdas solares: Isc, Voc, FF y eficiencia; utilizando los pigmentos de la flor de Jamaica no purificados extraídos con $\mathrm{HCl}$, ácido cítrico y TFA; y también con el pigmento estándar 
de rutenio. La mayor eficiencia obtenida de los pigmentos acidificados no purificados fue de $0,128 \%$ con $\mathrm{HCl}$. El pigmento purificado con hexano que reportó mayor eficiencia fue con $\mathrm{HCl}$ alcanzando $0,127 \%$, seguido de ácido cítrico y finalmente TFA, dichos valores se presentan en la Tabla 4.

Tabla 4. Comparación de los parámetros de caracterización de DSSC sensibilizadas con pigmentos de la flor de Jamaica extraídos con tres ácidos ( $\mathrm{HCl}$, cítrico y TFA) no purificados y de la celda estándar de Rutenio.

\begin{tabular}{c|c|c|c|c|c|}
\hline $\begin{array}{c}\text { Parámetros de } \\
\text { caracterización }\end{array}$ & $\begin{array}{c}\text { Unidad de } \\
\text { medida }\end{array}$ & Rutenio & HCl & $\begin{array}{c}\text { Ácidos } \\
\text { Cítrico }\end{array}$ & TFA \\
\hline Intensidad de corriente (Isc) & mA/cm ${ }^{2}$ & 19,586 & 0,451 & 0,255 & 0,388 \\
Voltaje de circuito abierto (Voc) & $(\mathrm{V})$ & 0,738 & 0,475 & 0,427 & 0,419 \\
\hline $\begin{array}{c}\text { Factor de llenado (FF) } \\
\text { Porcentaje de eficiencia } \\
\text { energética (n) }\end{array}$ & -- & 0,580 & 0,465 & 0,482 & 0,508 \\
\hline
\end{tabular}

Tabla 5. Comparación de los parámetros de caracterización de DSSC sensibilizadas con pigmentos de la flor de Jamaica extraídos con tres ácidos ( $\mathrm{HCl}$, cítrico y TFA) purificados y de la celda estándar de Rutenio.

\begin{tabular}{|c|c|c|c|c|c|}
\hline \multicolumn{1}{|c}{$\begin{array}{c}\text { Parámetros de } \\
\text { caracterización }\end{array}$} & $\begin{array}{c}\text { Unidad de } \\
\text { medida }\end{array}$ & Rutenio & HCl & $\begin{array}{c}\text { Ácido } \\
\text { Cítrico }\end{array}$ & TFA \\
\hline Intensidad de corriente (Isc) & $\mathrm{mA} / \mathrm{cm}^{2}$ & 19,586 & 0,533 & 0,218 & 0,140 \\
\hline Voltaje de circuito abierto (Voc) & $(\mathrm{V})$ & 0,738 & 0,482 & 0,394 & 0,377 \\
\hline Factor de llenado (FF) & -- & 0,580 & 0,513 & 0,431 & 0,453 \\
\hline $\begin{array}{c}\text { Porcentaje de eficiencia } \\
\text { energética (n) }\end{array}$ & $(\%)$ & 7,049 & 0,127 & 0,053 & 0,036 \\
\hline
\end{tabular}

Las curvas de corriente en función del voltaje (I vs V) de las celdas sensibilizadas con los pigmentos de flor de Jamaica purificados y no purificados se presentan en la Fig. 7.

Figura 7. Curvas características de las DSSC utilizando pigmentos de la flor de Jamaica. Los pigmentos fueron extraídos con tres ácidos diferentes: $\mathrm{HCl}$, ácido cítrico y TFA; además fueron purificados mediante un lavado con hexano. Los pigmentos con $\mathrm{HCl}$ no purificados $\mathrm{A}$ ) y purificados $\mathrm{B}$ ) presentaron mayor voltaje de circuito abierto (Voc) y corriente de cortocircuito (Isc).

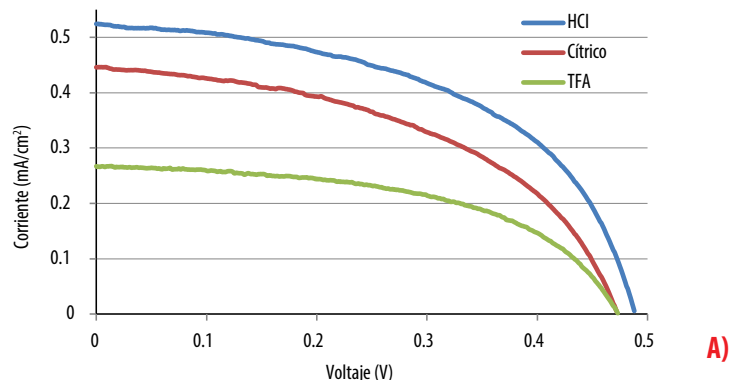




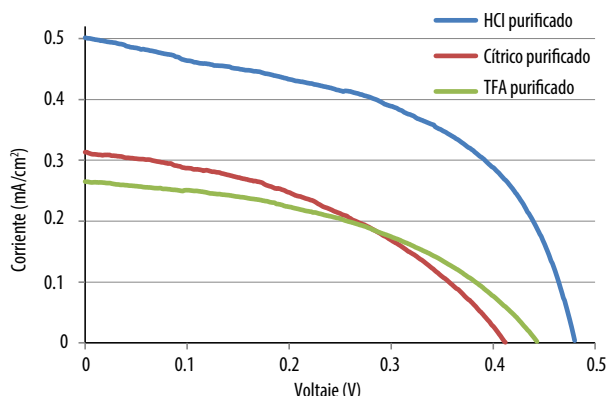

B)

\section{Estabilidad con el tiempo de DSSC}

En la Fig. 8 se presenta el porcentaje de variación de la eficiencia energética de las DSSC sensibilizadas con el pigmento de flor de Jamaica en un período de 30 días consecutivos.

Figura 8. Curvas de la estabilidad en función del tiempo de DSSC sensibilizadas con pigmentos de la flor de Jamaica acidificados. En los pigmentos no purificados A) se observa durante los 5 primeros días un incremento en la eficiencia con los tres ácidos de extracción; sin embargo, después del día 7 se presenta un descenso de la eficiencia hasta estabilizarse a partir del día 8. En los pigmentos purificados B) se presentó un incremento de la eficiencia durante los 5 primeros días, a excepción del pigmento extraído con $\mathrm{HCl}$, después de alcanzar el punto máximo de eficiencia, ésta descendió hasta que en el día 20 se mantuvo constante.
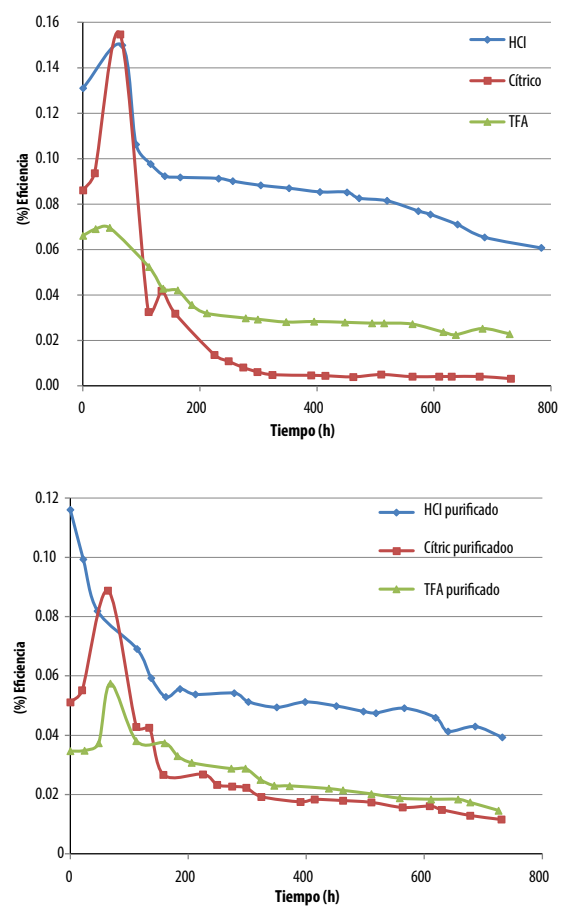

B) 


\section{DISCUSIÓN \\ Caracterización de la flor de Jamaica}

El alto contenido de ácidos orgánicos como el ácido ascórbico, cítrico, málico, tartárico, hibisco, succínico y oxálico en la flor de Jamaica son los causantes de valores de pH ácidos y por ende de altos valores de acidez en esta planta; este hecho se evidencia en la Tabla 1. Los valores de $\mathrm{pH}$ y acidez obtenidos son similares con trabajos experimentales, uno de los cuales reporta pH de 2,27 y acidez de 20,13 [28]. De igual manera, en otro experimento reportan 2,73 y 18,85 de $\mathrm{pH}$ y acidez respectivamente [12].

En cuanto al contenido de sólidos totales que indica la concentración de azúcares presentes, se obtuvo un valor similar al reportado en bibliografía que es de 5,5 Brix [12].

\section{Cuantificación de los pigmentos de la flor de Jamaica}

El aumento de la absorbancia del pigmento de la flor de Jamaica para la extracción con cada ácido, se debe a que ésta aumenta inversamente con el pH; es decir, que a menor $\mathrm{pH}$ mayor será la absorbancia [27]. Esto concuerda con los valores de $\mathrm{pH}$ de las mezclas metanol-ácido obtenidos, que fueron de 3,6; 3,0 y 2,3 para $\mathrm{HCl}$, ácido cítrico y TFA, respectivamente. Igualmente, los valores de $\mathrm{pH}$ antes mencionados se encuentran dentro del rango ( $\mathrm{pH}=1,0-4,0)$ en el que las antocianinas se encuentran en su forma más estable (catión flavilio) y por ende proporcionan al pigmento un color intenso y llamativo [26].

La extracción que reportó el mayor contenido de antocianinas fue el pigmento extraído con $\mathrm{HCl}$, seguido del ácido cítrico y finalmente con TFA. Del pigmento extraído con $\mathrm{HCl}$ se obtuvo 1 076,4 $\pm 6,7 \mathrm{mg}$ de antocianinas/100 $\mathrm{g}$ de muestra seca, valor que se asemeja al encontrado en bibliografía que fue $1386 \mathrm{mg}$ de antocianinas/100 g de muestra seca [12]. No obstante, las condiciones de extracción fueron diferentes a las utilizadas en esta investigación, ya que se usó como solvente de extracción etanol acidificado con $\mathrm{HCl}$ 1,5 N; superando el porcentaje de ácido añadido en este trabajo en 7 veces. Es por este motivo que se esperaba que el uso de metanol como solvente permita una mayor extracción de antocianinas al ser un compuesto más polar que el etanol, atrayendo a las antocianinas como glucósidos, que son las estructuras más polares que sus agliconas [18].

El uso de ácido cítrico en la extracción del pigmento permitió recuperar 997,4 mg de antocianinas/100 g de muestra seca; cantidad que supera a las cantidades encontradas en literatura que son $693 \mathrm{mg}$ de antocianinas/100 g de muestra seca [12].

Finalmente, la cantidad de antocianinas obtenidas con el uso de metanol acidificado con $0,5 \%$ de TFA fue de $895,1 \mathrm{mg}$ de antocianinas $/ 100 \mathrm{~g}$ de muestra seca; valor superior al reportado de otro experimento que fue de $606,67 \mathrm{mg}$ de antocianinas/100 $\mathrm{g}$ de muestra seca al utilizar metanol con 1\% de TFA [29].

\section{Identificación de antocianinas mediante TLC}

La cromatografía en capa fina del pigmento de flor de Jamaica extraído con $\mathrm{HCl}$ dio como resultado la separación de tres bandas. La tercera banda presente en la región UV no será considerada en la discusión, por no ser un compuesto de interés del estudio del 
presente trabajo. Además, cabe recalcar que ninguna de las bandas separadas coincidió con la banda del estándar; lo que confirmó que la cianidina 3-glucósido no está presente en la flor de Jamaica. Las bandas 1 y 2 se las pudo identificar primeramente por su color característico; la banda 1 de color rojo azulado que correspondería a la delfinidina y la banda 2 de color rojizo a la cianidina. En segundo lugar, el factor que indicaría el tipo de antocianidina al que corresponde cada banda separada es la polaridad, es así que la antocianina con mayor polaridad fue más retenida que la de menor polaridad. Es decir, que la banda 1 que corresponde a la delfinidina es más polar que la cianidina que es la banda 2. Esto se debe a que la delfinidina posee un radical $-\mathrm{OH}$ adicional aumentando así su polaridad con respecto a la cianidina que tiene en su lugar un hidrógeno [24].

Los espectros de las bandas separadas mediante TLC presentan una banda en la región UV y una en la región visible, tal como se observa en la Fig.5. En la región visible se identifica una minúscula protuberancia en los $445 \mathrm{~nm}$, que indica la presencia de un glicósido en su estructura; siendo la sambubiosa el disacárido para la flor de Jamaica [30]. En la Tabla 3 se comparan los valores de longitud de onda de cada antocianina separada y los valores estimados de longitud de onda de acuerdo a la regla de Woodward-Fieser que establece valores para los grupos funcionales orgánicos presentes en las estructuras de las antocianinas; siendo $275 \mathrm{~nm}$ para la delfinidina 3-sambubiósido y $268 \mathrm{~nm}$ para la cianidina 3-sambubiósido con un margen de error de $\pm 5 \mathrm{~nm}$; lo que permite confirmar la identificación de estas dos antocianinas presentes en el pigmento de la flor de Jamaica [23].

\section{Identificación de antocianinas mediante HPLC}

La separación y retención de cada antocianina es contraria a la presentada en capa fina; ya que se utilizó una columna C-18 en fase reversa, lo que indica que el compuesto antocianónico menos polar será retenido durante más tiempo en la columna. Es decir, que la primera banda del cromatograma identificada a los 23,220 minutos corresponde a la delfinidina 3-sambubiósido ya que es más polar que la cianidina 3-sambubiósido que es retenida más tiempo, hasta los 26,804 minutos; hecho que ratifica la separación de las antocianinas mediante TLC. Este resultado se compara con otros ya reportados, en los que se afirma que la primera banda obtenida en la separación de antocianinas de la flor de Jamaica mediante HPLC corresponde a la delfinidina 3-sambubiósido y el segundo a la cianidina 3-sambubiósido con tiempos de retención de 12,681 y 13,389 minutos respectivamente [20]. De la misma manera, otro reporte presenta el mismo orden de elución de las dos antocianinas mencionadas anteriormente a los 8,0 y 10,5 minutos respectivamente. La diferencia en los tiempos de retención de HPLC se atribuye a la fase móvil utilizada en cada experimento [29].

\section{Caracterización de DDSC}

La mayor eficiencia obtenida de los pigmentos acidificados no purificados fue de $0,128 \%$ con $\mathrm{HCl}$. Este valor es similar al reportado en otro experimento en el que se utilizó pigmento extraído con etanol acidificado con $\mathrm{HCl}$ y logró una eficiencia del $0,11 \%$ [10]. Igualmente se reporta $0,10 \%$ de eficiencia con pigmento de flor de Jamaica extraído con etanol, aunque no especifica el ácido utilizado [13]. A pesar de no encontrar reportes de eficiencias utilizando ácido cítrico y TFA, los resultados obtenidos de 0,087\% y $0,064 \%$ fueron de gran utilidad para establecer una relación de la eficiencia con el 
contenido total de antocianinas presentadas para cada ácido en la Tabla 2. Siendo mayor la eficiencia cuan mayor es el contenido de antocianinas, ya que en el equilibrio existirá mayor adsorción química y mayor transferencia de carga en la celda [9]. Además, al comparar el pH del pigmento de la Tabla 2 con la eficiencia de las celdas, se tiene que ésta aumenta conforme aumenta el pH del pigmento; esto se contrapone con trabajos realizados en los que se tiene una relación inversa entre el pH y la eficiencia; sin embargo, se debe tomar en cuenta que en estos trabajos se estudió efecto del pH utilizando $\mathrm{HCl}$ y en este experimento se emplearon 3 ácidos diferentes [1].

Los pigmentos purificados con hexano mantuvieron la misma relación de los pigmentos no purificados con el contenido de antocianinas; es decir que la eficiencia fue mayor mientras mayor fue el contenido de antocianinas totales. Por el contrario, al comparar las eficiencias obtenidas con cada ácido se observa que, con excepción del $\mathrm{HCl}$, la eficiencia disminuye cerca de la mitad del valor al purificar los pigmentos. Esto puede atribuirse a una posible interferencia de los residuos de hexano con el proceso de pigmentación del sustrato $\left(\mathrm{TiO}_{2}\right)$, lo cual se puede apreciar visualmente. Todo esto se observa a pesar de que el tiempo de pigmentación no varió en ningún caso. Por lo tanto, se puede afirmar que el tipo de ácido utilizado en la extracción de los pigmentos y su posterior purificación afecta la pigmentación del $\mathrm{TiO}_{2}$ y por ende la eficiencia energética.

El factor de llenado es importante en la caracterización de DSSC porque relaciona la potencia máxima generada con la potencia si la celda fuese ideal, es decir asumiendo que no existen ni pérdidas ni resistencia al paso de corriente. El valor ideal del FF es 100\% [13]. Es así que se compararon los valores de FF de las DSSC obtenidos con los pigmentos de la flor de Jamaica y con el pigmento de Rutenio. La celda estándar de rutenio reportó una eficiencia de 7,05\% y un FF de 0,58. Los pigmentos que reportaron los mejores valores de FF fueron con TFA no purificado de 0,508 y con $\mathrm{HCl}$ purificado de 0,513 pero que sin embargo están por debajo del estándar de rutenio. Esto indica que los fenómenos de recombinación y la eficiencia de extracción de carga son similares en todos los casos estudiados. En la Fig.7 se presentan las curvas de corriente voltaje de las DSSC. En estas curvas se observa que el voltaje de circuito abierto está cercano al 0,5 V , el cual es menor al de 0,74 V correspondiente a la celda de referencia de rutenio. Esta diferencia se puede atribuir a la estructura molecular del pigmento y al tiempo de recombinación de los electrones, los cuales afectan la densidad de electrones libres en la banda de conducción del TiO2 y modifican el nivel energético de Fermi; y por tanto el voltaje de circuito abierto [31].

\section{Estabilidad con el tiempo de DSSC}

En la Fig. 8. se observa que las celdas sensibilizadas con todos los pigmentos analizados exceptuando el acidificado con $\mathrm{HCl}$ purificado mostraron un incremento de la eficiencia durante los primeros días. Este incremento se puede interpretar como un período en el cual el electrolito se difunde por todo el volumen del $\mathrm{TiO}_{2}$, es decir que se necesita de cierto tiempo para que la interacción entre el $\mathrm{TiO}_{2}$ y el electrolito sea la adecuada y aumente la eficiencia de la celda.

Por otro lado, la pérdida de eficiencia energética puede atribuirse a la vaporización del electrolito utilizado perdiendo así el principal contacto entre la capa de $\mathrm{TiO}_{2}$ y el contra-electrodo interrumpiéndose el ciclo de generación de electricidad; y por ende 
dismuyendo la eficiencia de la celda [32]. Otro motivo puede ser la degradación de las antocianinas de los pigmentos que pueden contribuir a la disminución paulatina de las eficiencias energéticas al no proporcionar la misma cantidad de electrones al $\mathrm{TiO}_{2}$ [11]. Por lo tanto, sería de gran utilidad realizar un posterior estudio sobre los factores que influyen en la degradación de los pigmentos naturales.

En conclusión, se puede afirmar que los extractos de la flor de Jamaica tienen dos antocianinas que son la delfinidina 3-sambubiósido y la cianidina 3-sambubiósido presentes en diferente proporción. La antocianina presente en mayor cantidad es la delfinidina 3-sambubiósido, que duplica el contenido de cianidina 3-sambubiósido. Utilizando como fase móvil una solución de n-butanol, ácido fórmico y agua en relación 10:15:40, se obtuvo una relación de frentes de 0,14 y 0,20 para las bandas de antocianinas separadas, 1 y 2 respectivamente. El tipo de ácido usado para controlar el pH durante el proceso de extracción tiene una influencia positiva en la eficiencia de conversión energética de la celda, siendo el $\mathrm{HCl}$ el que dio mejores resultados. La purificación de los pigmentos con hexano, un solvente no polar, disminuye la eficiencia de conversión energética aparentemente debido a una falta de pigmentación del $\mathrm{TiO}_{2}$.

\section{AGRADECIMIENTOS}

La presente investigación fue financiada con el Proyecto de Investigación Multidisciplinario PIMI-14-08 de la Escuela Politécnica Nacional, con la colaboración del Laboratorio de Nanoestructuras de la Facultad de Ciencias Químicas de la Universidad Central del Ecuador y Laboratorio de Análisis Instrumental de la Universidad Politécnica Salesiana.

\section{CONTRIBUCIÓN DE LOS AUTORES}

Cristian Santacruz concibió la investigación; Cristian Santacruz y Marcelo Salvador proveyeron los recursos para la investigación: equipos, materiales y reactivos; Mirian Sangoluisa diseñó, desarrolló la metodología y adquirió los datos experimentales; Cristian Santacruz desarrolló el software para la determinación de las eficiencias de las celdas DSSC; Cristian Santacruz y Mirian Sangoluisa realizaron el análisis e interpretación de los daros experimentales; Mirian Sangoluisa redactó el manuscrito; Cristian Santacruz y Marcelo Salvador revisaron críticamente el contenido intelectual del manuscrito; Mirian Sangoluisa elaboró las tablas y figuras; Mirian Sangoluisa tomó la fotografía de la Fig.4. 


\section{REFERENCIAS}

[1] Wongcharee, K. Meeyoo, V. \& Chavadej, S. (2007). Dye-sensitized solar cell using natural dyes extracted from rosella and blue pea flowers. Solar Energy Materials \& Solar Cells. 91(2007). 566-571. D0l: http://dx.doi.org/10.1016/j. solmat.2006.11.005

[2] Susanti, D. Nafi, M. Purwaningsih, H. Fajarin, R.\& Kusuma, G. (2013). The preparation of Dye Sensitized Solar Cell (DSSC) from TiO and Tamarillo Extract. ScienceDirect. 9 (2014). 3-10. D0l: http://dx.doi.org/10.1016/j.proche.2014.05.002.

[3] Grätzel, M. (2003). Dye-sensitized solar cells. Journal of Photochemistry and Photobiology C. 4 (2003). 145-153. D0I: http://dx.doi.org/10.1016/S1389-5567(03)00026-1.

[4] Duval, J. (2010). Estudio teórico-práctico de fotoelectrodos base Ti02 para uso en celdas solares. (Tesis para obtener el grado de Master en Tecnología Avanzada). Instituto Politécnico Nacional, Tamaulipas, México. Recuperado de: http://itzamna.bnct.ipn.mx:8080/dspace/bitstream/123456789/9830/1/186.pdf.

[5] Alvarado, S. (2011). Sintesis de Óxidos de Titanio (TiO2) y Óxidos de Zinc (ZnO) dopados para su empleo en Celdas Solares. (Tesis profesional presentada como requisito parcial para obtener el título en Licenciatura Química). Universidad de la Américas, Puebla, México. Recuperado de: http://catarina.udlap.mx/u_dl_a/tales/documentos/lqu/alvarad

[6] Sánchez, M. (2014). Nuevos sensibilizadores de Rutenio-Bipiridina para células solares sensibilizadas por colorantes. (Tesis doctoral en (iencias). Universidad Autónoma de Madrid, Madrid, España. Recuperado de: http://hdl.handle. net/10486/666665.

[7] Flores, N. (2014). Determinación de la eficiencia energética de celdas solares sensibilizadas con pigmentos obtenidos de extractos naturales. Procesos microbiológicos y nanopartículas de germanio. (Trabajo final de graduación para optar por el grado de Licenciatura en Ingeniería Química). Universidad de Costa Rica, Costa Rica. Recuperado de: http://www. kerwa.ucr.ac.cr/handle/10669/16744.

[8] Hug, H. Bader, M. Mair, P. y Glatzel, T. (2014). Biophotovoltaics: Natural Pigments in dye/Sensitized solar cells. Science Direct, 115(3), 216-225. DOl: http://dx.doi.org/10.1016/j.apenergy.2013.10.055.

[9] Cabrera, M. (2014). Estudio de colorantes fotosensibles obtenidos de tres plantas de la región sur del Ecuador para ser aplicadas en celdas solares mediante espectrometría UV-Visible. (Trabajo de fin de titulación para optar por el Título de Ingeniero Químico). Universidad Técnica Particular de Loja, Loja, Ecuador. URL: http://dspace.utpl.edu.ec/ handle/123456789/10724.

[10] Mansa, R. Govindasamy, G. Farm, Y. Bakar, H. Dayou, J. y Stephen, C. (2014). Hibiscus Flower Extract as a Natural dye sensitizer for a dye-sensitized solar cell. Journal of Physical Science. 25(2). 85-96. Recuperado de: http://web. usm.my/ jps/25-2-14/25-2-7.pdf.

[11] Aguilera, M. Reza, M. Che, R\& Meza, J. Propiedades funcionales de las antocianinas. Revista de Ciencias Biológicas y de la Salud. 8 (2). 16-22. Recuperado de: http://biotecnia.ojs.escire.net/index.php/biotecnia/article/view/81/75.

[12] Azza, A. Ferial, A y Esmat, A. (2011). Physico-chemical properties of natural pigments (anthocyanin) extracted from Roselle calyces (Hibiscus Sabdariffa). Journal of American Science, 7(7), 445-456. Recuperado de: http://www. jofamericanscience.org/journals/am-sci/am0707/067_6293am0707_445_456.pdf.

[13] Calero, C. (2016). Construcción y caracterización de celdas solares sensibilizadas por pigmentos naturales extraídos de plantas existentes en el Ecuador y determinación de la eficiencia de conversión energética. (Tesis previa a la obtención del grado de Máster en Eficiencia Energética). Escuela Politécnica Nacional, Quito, Ecuador. Recuperado de: http:// bibdigital.epn.edu.ec/bitstream/15000/15320/1/CD-7036.pdf.

[14] Cid, S. y Guerrero, J. (2014). Roselle calyces particle size effect on the physicochemical and phytochemicals characteristics. Journal of Food Research. 3(5). 83-94. Dol: http://dx.doi.org/10.5539/jfr.v3n5p83.

[15] Association of Official Analytical Chemist (AOAC). (2001). AOAC 10.035: Determinación de pH en frutas y vegetales. Recuperado de: http://www.usc.es/caa/MetAnalisisStgo1/PROGRAMA.htm.

[16] Association of Official Analytical Chemist (AOAC). (2003). AOAC 22.061: Determinación de la acidez titulable en frutas y hortalizas elaboradas. URL: http://www.usc.es/caa/MetAnalisisStgo1/PROGRAMA.htm.

[17] International Organization for Standardization, ISO. (2003). ISO:2173:2003 Fruitand vegetable products --Determination of soluble solid-Refractometric method. URL: https://www.iso.org/obp/ui//\#iso:std:iso:2173:ed-2:v1:en. 
[18] Camelo, G. (2013). Caracterización química y colorimétrica de cultivares de Jamaica (Hibiscus sabdariffa L.). (Tesis para obtener el grado de maestría en Ciencias en Desarrollo de Productos Bióticos). Instituto Politécnico Nacional, Morelos, México. Recuperado de: http://tesis.ipn.mx:8080/xmlui/handle/123456789/12420.

[19] Menéndez, W. (2008). Obtención de colorante para su uso en yogurt a partir de la flor de Jamaica (Hibiscus Sabdariffa) y del mortiño (Vaccinium myttillus L.). (Tesis de grado previo a la obtención del título de Ingeniero de alimentos). Escuela Superior Politécnica del Litoral, Guayaquil, Ecuador. Recuperado de: https://www.dspace.espol.edu.ec/ bitstream/123456789/11951/3/CAPITULOSSS.pdf.

[20] Obouayeba, P. Djyh, B. Diabate, S. Djaman, J. N'Guessan, J. Kone, M. y Kouakou, T. (2014). Phytochemical and Antioxidant Activity of Roselle (Hibiscus Sabdariffa L.) Petal Extracts. Research Journal of Pharmaceutical, Biological and Chemical Sciences, 5(2). 1453-1465. Recuperado de: http://www.rjpbcs.com/pdf/2014_5(2)/\%5B175\%5D.pdf.

[21] Rodríguez, L. y Wrolstad, R. (2012). Anthocyanin's. Handbook of Food Analytical Chemistry, 6(1), 7-69. Recuperado de: http://onlinelibrary.wiley.com/doi/10.1002/0471142913.faf0101s00/references.

[22] Laboratorios Camag. (2011). Camag application notes: Fingerprint Analysis/Screening of Medicinal Plants. Recuperado de: http://www.camag.com/media/2WG85642/CAMAG_Application_Notes_Herbals.pdf.

[23] Sánchez, M. (2010). Comprobación de la actividad tintorera en fibras orgánicas y sintéticas de a Berberis hallii. (Tesis de grado previa la obtención del título de Bioquímico Farmacéutico). Escuela Politécnica de Chimborazo, Riobamba, Ecuador. Recuperado de: http://dspace.espoch.edu.ec/bitstream/123456789/698/1/56T00228.pdf.

[24] Peguero, F. (2007). Perfil de antocianinas de tres variedades de frijol negro (Phaseolus vulgaris L.) cultivadas en Honduras. (Proyecto especial presentado como requisito parcial para optar al título de Ingeniero Agroindustria Alimentaria en el grado académico de licenciatura). Universidad Zamorano, Honduras. Recuperado de: http: //bdigital.zamorano.edu/ bitstream/11036/681/1/T2467.pdf.

[25] Namin, A. Jivacate, C. Chenvidhya, D. Kirtikara, K. Thongpron (2012) Construction of Tungsten Halogen, Pulsed LED, and Combined Tungsten Halogen-LED Solar Simulators for Solar Cell I-V Characterization and Electrical Parameters Determination. International Journal of Photoenergy. 2012. 1-9. Recuperado de: http://dx.doi. org/10.1155/2012/527820

[26] Sordo, J. (2004). Papel antioxidante de Antocianinas presentes en la Col Morada (Brassica oleracea), en Sistemas Oxidantes de FeCl3/Ac. Ascórbico en la Peroxidación del Ácido Linoleico. (Tesis profesional para obtener el título en Licenciatura en Quimicofarmacobiología). Universidad de las Américas, Puebla, México. Recuperado de: http://catarina.udlap. $\mathrm{mx} / \mathrm{u}$ _dl_a/tales/documentos/lqf/sordo_s_.p/.

[27] Cid, S. \& Guerrero, J. (2014). Roselle calyces particle size effect on the physicochemical and phytochemicals characteristics. Journal of Food Research. 3(5). 83-94. Recuperado de: http://dx.doi.org/10.5539/jfr.v3n5p83.

[28] Prenesti, E. Berto, S. Daniele, P. \& Toso, S. (2005). Antioxidant power quantification of decoction and cold infusions of Hibiscus Sabdariffa flowers. Food Chemistry. 100(2007). 433-438. Recuperado de: https://iris.unito.it/retrieve/ handle/2318/4687/997/Hibiscus.pdf.

[29] Galicia, L. Salinas, Y. Espinoza, B. y Sánchez C. (2008). Caracterización fisicoquímica y actividad antioxidante de extractos de Jamaica (Hibiscus sabdariffa L.) nacional e importada. Revista Chapingo Serie Horticultura. 14(2). 121129. Recuperado de: $h$ ttp://www.redalyc.org/articulo.oa?id=60911556003.

[30] Santacruz, L. (2011). Análisis químico de antocianinas en frutos silvestres colombianos. (Tesis de maestría en Ciencias Químicas). Universidad Nacional de Colombia, Bogotá, Colombia. Recuperado de: http://www.bdigital.unal.edu. co/5351/.

[31] Grätzel, M. (2001). Photoelectrochemical Cells. Nature. 414(6861). 338-344. D0l: http://dx.doi.org/10.1038/35104607

[32] Oku, T. Kakuta, N. Kobayashi, K. Suzuki, A \& Kikuchi K. (2011). Science Direct. 21(2011). 122-126. D0l: http://dx.doi. org/10.1016/S1002-0071(12)60045-8. 